\title{
A SYSTEMS-BASED FRAMEWORK FOR CONTINUOUS IMPROVEMENT: A SERVICE SECTOR APPLICATION
}

\author{
Richard A. Reid \\ University of New Mexico \\ Albuquerque, NM \\ Elsa Leong Koljonen \\ Intel Corporation \\ Chandler, AZ
}

\begin{abstract}
Based on the Deming Cycle and the Jointer 7 Step Method, a new systemsbased framework for performing continuous improvement has been developed. This new conceptual framework embodies the systems concepts of leverage, synergy, and sensitivity analysis. This paper demonstrates how these systems concepts could be applied to improve customer satisfaction in a small, recentlyestablished, law firm. The resultant customer-focused action plan is designed to avoid any negative effects associated potential suboptimization that might occur when an improvement team focuses on a single organizational process.
\end{abstract}

\section{Introduction}

The two major cornerstones of operations management are quality and productivity. From an internal perspective, managers concerned with the day-to-day operations have always sought to improve customer satisfaction through increasing the quality and productivity of the processes designed to perform work in organizations. The Total Quality Management (TQM) philosophy with its major focus on continuous improvement (CI) has promoted the mobilization of process improvement teams. In many organizations, these teams of employees have been instrumental in advocating a never-ending process of performance improvement (Cheney, et al., 1994).

By improving processes by which work is performed, the focus is on continuously and incrementally improving everything associated with designing, creating, and delivering satisfaction to a firm's customers. The rationale for $\mathrm{CI}$ is that customer needs are not static, but are dynamic and change continually. As a result, although a firm's outputs and/or its processes may be considered innovative today, competitive forces may render them commonplace tomorrow. That is, today's "order winners" readily become tomorrow's "order qualifiers" (Hill, 1994). Thus, a firm is only able to maintain its competitiveness in a dynamic marketplace by continuously improving. In short, $\mathrm{CI}$ can be an effective operations strategy if it (1) addresses the needs of the customers, (2) seeks to improve on the 
competencies of the competitors, and (3) is able to reflect desired changes in the firm's internal capacities and capabilities (Schonberger \& Knod, 1997).

W. Edwards Deming has stated that managers must constantly and forever improve their production and service processes. Furthermore, he notes that improvement is not just a "one-time effort" and that managers are obligated to continuously search for and implement ways to reduce waste and improve quality (Walton, 1986). Juran (1989) verbalizes his agreement in the following two imperatives: (1) "to maintain and increase sales income, companies must continually evolve new product features and new processes to produce these features", and (2) "to keep costs competitive, companies must continually reduce the level of product and process deficiencies." Moreover, he believes that both customer needs and competitive cost structures are moving targets. From an international perspective, kaizen, is the name that the Japanese have given to the concept of continuous incremental improvement. It is considered to be the single most important concept in Japanese management and the key to their competitive success (Imai, 1986) because it is operationalized throughout the total organization and expected to be practiced by all employees at every level. Kaizen means making changes for the better on an ongoing, never-ending, basis.

Continuous improvement is usually embodied in a structured approach which emphasizes the need to establish an organizational commitment to a systematic, continual improvement in capability, reliability, and efficiency of business processes (Conway, 1993). This paper presents an alternative approach to structuring the $\mathrm{CI}$ process that incorporates systems thinking. Based on the Deming Cycle and the Jointer 7 Step Method, this new framework incorporates several concepts from systems theory. Discussion is focused on the embodiment of these system concepts in the framework's procedures for creating a systems-oriented action plan. Insights gained by sequentially applying these systems concepts are illustrated for a small, recently-formed, law firm in Hong Kong. Some conclusions are drawn relative to the practical applicability of this approach.

\section{A Systems Perspective on Continuous Improvement}

Although there are many approaches for structuring the implementation of CI, two of the most common include the Shewhart or Deming Plan-Do-Check-Act Cycle (Deming, 1982 and 1986) and the Jointer 7 Step Method (Jointer Associates, 1990). Both approaches focus on the goal of improving work-performing processes by increasing customer satisfaction. Figure 1 displays the important characteristics and content of the four stages in Deming's structured approach.

Figure 2 presents the Jointer 7 Step Approach to Cl. From problem identification to deep cause determination to solution determination to implementation to checking and standardization, the Jointer Method provides a comprehension guide to process improvement. Both approaches emphasize an improvement logic that is inherent to implementing change by focusing on what to change, what to change 
to, and how to cause change. Moreover, each framework is designed to support a team-based approach to $\mathrm{CI}$.

Figure 1

- Standardize desired improvements

- Formalize "current best approach"

- Communicate results broadly

- Celebrate team success

- Identify next improvement
- Assemble right people on team

- Gather all available data

- Understand customer's needs

- Describe the process that surrounds the problem

- Deternine root cause(s)

- Design action plan

- Develop plarvitain the people
- Summarize and analyze data

- Evaluate results relative to targets

- Understand/document differences

- Review any problems/errors

- Record what was leamed

- Specify any remaining issues or unintended consequences

These two approaches provide a structure for improving organizational processes. It is common to describe a process as a series of interrelated tasks directed toward accomplishing a desired outcome. From this perspective, it is possible to consider any task as a component of one or more processes. It is noteworthy that a problem is often associated with a task or group of tasks, and therefore, resides within a process. This implies that solving a problem will usually involve some modifications of the problem's environment and that this may include changes in (1) neighboring tasks, (2) task interfaces or (3) linkages with other processes. Thus, if a series of related tasks is considered to be a process, then it is appropriate to consider a group of related processes as a system (Melan, 1993). Since a system may encompass a large number of processes, it is often prudent for improvement teams to focus their efforts on a single process rather than a collection of processes. Although there is some risk associated with suboptimizing, Scholtes (1988) believes that team-based improvements have a great probability for success if the team focuses its initial efforts in a smaller single domain prior to consideration of the entire system. 
Figure 2

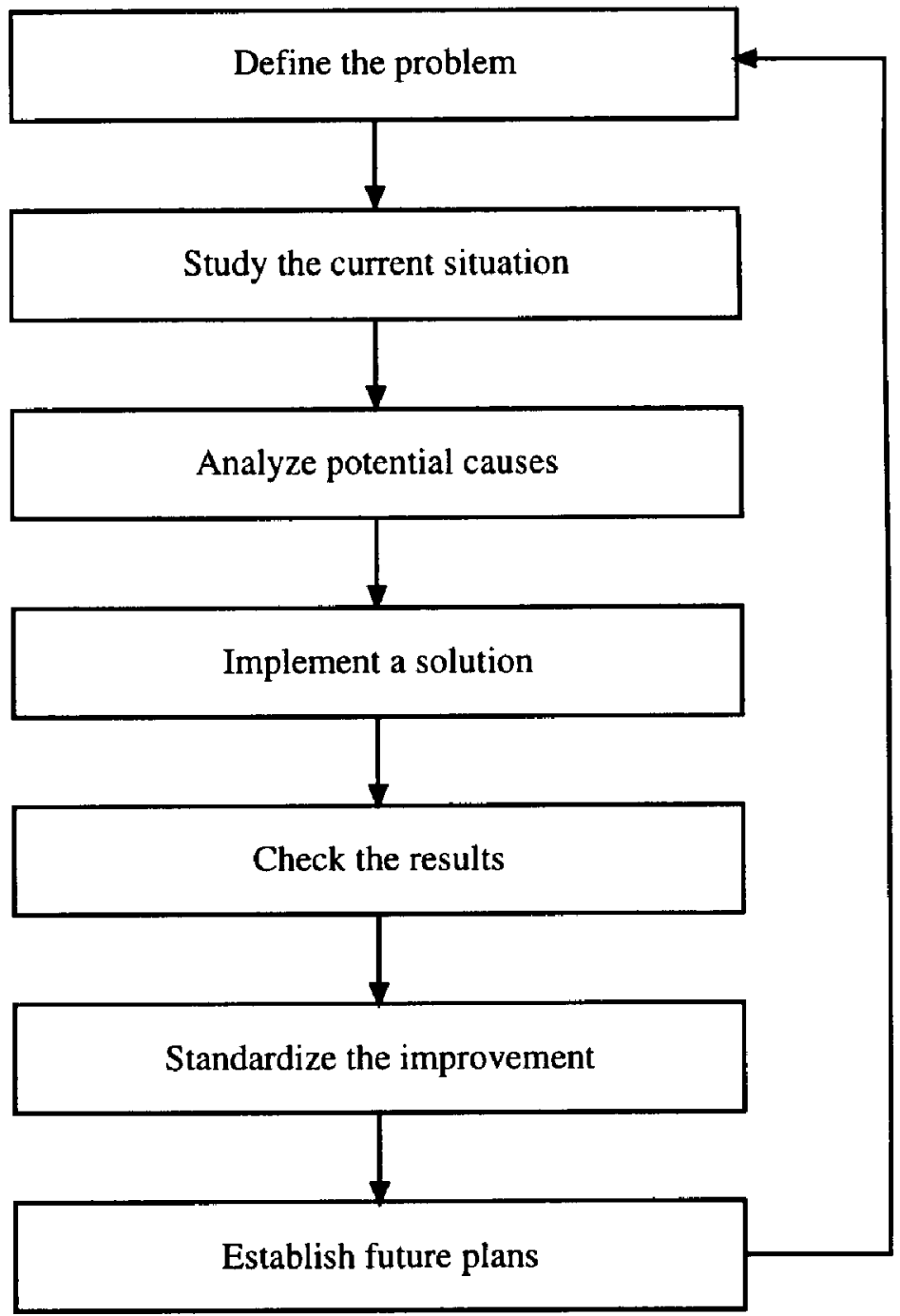

While it may not be effective to consider an entire system for team-based improvement efforts initially, it is possible to incorporate some system concepts into the process improvement approach. Accompanied by a set of detailed guidelines for each of the seven steps, Figure 3 presents a new conceptual framework for integrating some systems thinking into an approach to process improvement. This framework incorporates the underlying CI logic along with many of the concepts, ideas, and steps from the Deming Cycle and the Jointer 7 Step Method. Although each of the seven steps in the new framework is important, most improvement teams will spend most of their time and effort in project planning which encompasses the first four steps. 
Figure 3

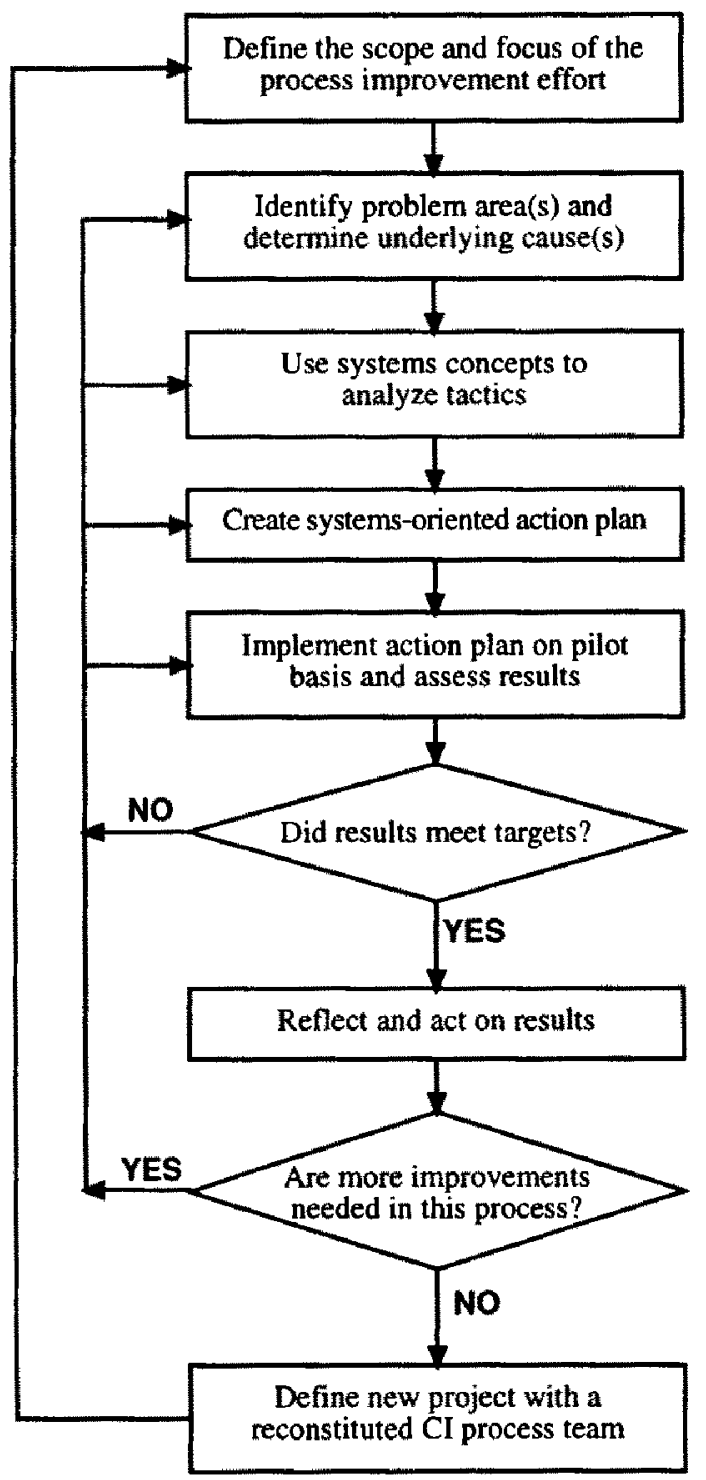

\section{Detailed Guidelines}

1. Project team sets improvement goal

2. Determine project boundaries

3. Collect operations data on current situation

1. Summarize and analyze data

2. Define problem area

3. Prioritize problens

4. Identify possible cause(s) for major problems

1. Identify solution alternatives for major problems

2. Determine high leverage improvement areas

3. Perform sensitivity analyses

1. Apply the concept of synergy

2. Design action plan

3. Establish performance targets

1. Follow plan and document results

2. Review results relative to targets.

1. Institutionalize desired changes

2. Disseminate new knowledge throughout the organization

3. Continue improvement effors

1. Develop new initiative for improvement

2. Assure lessons learned are preserved

Step 1 - Define the Project's Scope. In this initial step, the improvement project's purpose and scope are established. This activity requires operations performance data to be collected relative to the current situation. Although these data are necessary to provide an empirical base for assessing any problem areas, they often just 
document the symptoms of a problem. However, they help to narrow the project's focus and establish boundaries on the investigation by providing a preliminary indication on the location of current process failure(s). Moreover, they may provide insight into an appropriate composition of knowledge, skills, and capabilities that are needed among team members. Once established, the team may use various forms of brainstorming to help further define problems and identify issues of concern.

Step 2 - Identify Problems and Determine Probable Causes. Data previously collected are summarized and analyzed in order to isolate the process that contains the problems or is responsible for the issues of concern. This allows the team to focus on a given process whose performance needs to be improved. Next, the process is fully described, often with a flowchart, and suspect points of failure are identified. All problems are listed and major problem areas are prioritized relative to their importance. Data reflecting customer satisfaction and/or opinions are often used to ascertain the relative importance of areas of concem. A variety of the team-based TQM tools (Brassard \& Ritter, 1994) such as a fishbone chart and the interrelationship digraph may be utilized to describe all possible causes responsible for the problem areas. The why-why diagram (Tague, 1995) may be used to help probe into the underlying causes responsible for the problem area(s). The designation of the underlying causes of the major problems is a primary output of this step.

Step 3 - Create and Analyze Solution Alternatives. This step seeks to prescribe the tactics that will be used to address the major problem areas by generating and evaluating improvement alternatives. Since effective cause analysis is a prerequisite for effective solution generation, it may be necessary to further analyze the identified problem causes and the current situation. This can be done by using Theory of Constraint logic tree tools such as the current and future reality trees, or the conflict resolution diagram (Goldratt, 1994; Dettmer, 1997). Additionally, insight into potential solution effectiveness may be gained through imitating systemic behavior through simulation models (Koljonen \& Reid, 1998a). Those solution approaches considered to be high leverage are often the most desirable. Leverage is a systems principle that supports the idea that small, well-focused, and timely action(s) can produce significant improvements (Senge, 1990). After determining high leverage potential solutions, a sensitivity analysis of the assumptions or estimates underlying leverage computations is needed to establish their robustness. Sensitivity analysis is a systems concept that can be defined as examining the impact on expected outcomes of reasonable changes in parameter value estimates (Eschenbach, 1992).

Step 4 - Create Action Plan. The focus is on developing an effective action plan that considers addressing several major problems simultaneously by incorporating multiple alternatives within a coordinated set of actions. The key here is to look for some potential synergistic relationships among the various solution approaches to the identified major problems. Synergy is a systems concept in which the effect of several actions is greater than the sum of their individual effects because the interaction between the actions creates a disproportional effect on the desired result (Schoderbek, et al., 1990). The action plan needs to be specific enough to guide the change process. It usually includes scheduling the sequence of changes, identifying resources, assigning responsibilities, hiring new 
staff, and/or training personnel. Prior to implementation, it is necessary to set performance targets and establish methods to monitor the results of the planned changes.

Step 5 - Implement and Assess Pilot Project. Usually the action plan is implemented on a small scale or as a pilot project. During this step, it is necessary to: (1) follow the action plan, (2) document any changes to the plan along with the rationale for the change, and (3) measure improvement from both the customer's and the firm's perspective. These steps are suggested so that the $\mathrm{Cl}$ team will maximize its learning from this experience. Comparisons are made between actual and expected results of the implemented changes. The idea is to determine if the planned changes were successful in addressing the core problem and whether the symptoms have been diminished. Equally important is the identification and mitigation any unintended negative consequence resulting from change.

If the implementation was only partially successful, or worst, unsuccessful, then it is usually necessary for the $\mathrm{CI}$ team to reassess the situation and revisit one of the previously completed steps. For example, step 2 is revisited if the underlying cause(s) of any major problem(s) were incorrectly determined. Step 3 is revisited if one or more solution alternatives were inappropriately conceived. Step 4 is revisited if the action plan was poorly designed. Finally, step 5 is revisited if the action plan was poorly implemented. Obviously, the $\mathrm{Cl}$ team would prefer not to have to revisit any of the previous steps. If results are acceptable relative to previously specified performance targets, then the team implements the next step.

Step 6 - Reflect On and Institutionalize Changes. In this step, emphasis is directed toward determining (1) what was learned, (2) what can be generalized for use in future improvement efforts, and (3) what remains dysfunctional. First, successful improvements are codified as the new standard operation(s). Changes are institutionalized to assure that progress made is permanently captured in revised policies, procedures, and processes. Moreover, the new, improved change is widely disseminated throughout the organization and selected aspects of the CI team's experience are documented and/or extrapolated for use in future improvement activities. The improvement process is continued by either (1) developing a new initiative for improving some aspect of the original process that did not totally measure up to prior expectations or (2) identifying a new problem area or issue of concern within the firm where improvement is sought or the new lessons learned can be applied. In the latter case, the CI team would go to the next step.

Step 7 - Define a New CI Project. The focus of this step is to create a new CI initiative and bring together a knowledgeable and qualified team to plan and implement required process changes. In short, it is necessary to ceaselessly iterate through the new $\mathrm{Cl}$ framework that incorporates systems thinking into a systematic approach to process improvement. Moreover, this step requires that previous lessons learned are not lost but are documented and disseminated in an effective manner to other organizational units. Continuous improvement can be an effective operations strategy for remaining competitive in a dynamic marketplace. As such, it is essential to address new arenas in need of process improvement and/or apply what has been leamed to similar organizational situations. New arenas of application may require the $\mathrm{Cl}$ team to have new knowledge and/or capabilities, which in tum, may necessitate the reconstitution of its membership. 
As presented in Figure 3, the new framework for process improvement seeks increased effectiveness by incorporating some systems concepts into its approach. In order to highlight the potential impact of these concepts, they will be applied to a small law firm in need of improved customer service. Figure 4 provides a flowchart for sequentially using these concepts to help create an action plan. First, the major problem area(s) are identified. Then a matrix is used to structure the determination of the potential leverage associated with each problem area. Next, a sensitivity analysis is performed to determine the impact of reasonable changes in initial estimates used to compute leverage factors. Finally, the situation is examined for potential synergistic relationships and the action plan is completed.

Figure 4

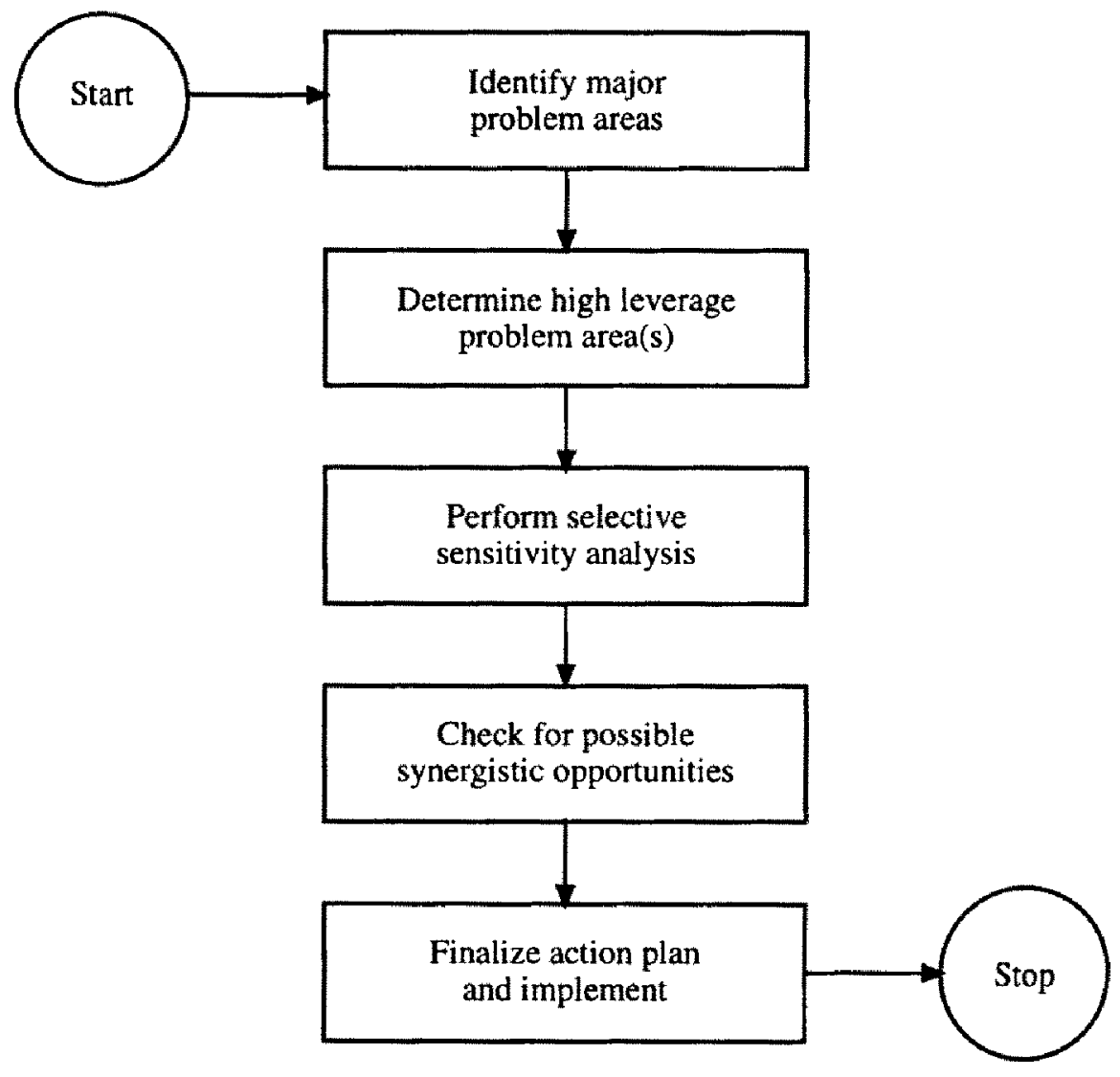

Case Study: Application in the Service Sector

The purpose of this case study is to illustrate how the system concepts associated with a new framework for process improvement could be applied to improve customer satisfaction in small service sector firm. A recently-established law firm in Hong Kong specializes in patents and trade mark applications, commercial 
contracts, and real estate transactions. It consists of three partners, three article clerks who are solicitors-in-training, three secretaries, two junior clerks, and two receptionists. For the most part, clients from the partner's previous practices provide the main customer base. Under the laws of Hong Kong, lawyers are not allowed to actively solicit new business through traditional marketing approaches such as advertising. Therefore, new clients are mainly generated by referrals from current customers. As a result, customer satisfaction is of paramount importance to the new firm's survival and future success.

The firm solicited feedback from new customers over a recent three week period. Based on interviews with the law firm's senior partners, selected clients, and a review of the service quality and system effectiveness literature, a survey instrument was designed and administered as part of performing a Walk-Through Audit (WTA) at the firm. A WTA is a performance assessment tool designed to systematically evaluate customer perceptions of the complete service creation and delivery process and the total service package offered by a service organization (Fitzsimmons \& Fitzsimmons, 1998; Koljonen \& Reid, 1998b). Based on new client experience, the responses to 25 questions were rated on a scale from 1 to 5 , with 1 reflecting the lowest rating and worst possible outcome and 5 representing the best and most favorable scenario.

\section{Major Problems}

The client-based results of the WTA revealed four major areas of concern associated with the service delivery process. These problem areas, each receiving an average client rating of less than 4.0, are as follows: (1) appointment time convenience (3.53), (2) law office accessibility (3.67), (3) law office appearance (3.33), and (4) time delay estimate prior to meeting with legal staff (3.40). Using the same survey method, a benchmark study at four well-established and highly respected Hong Kong law firms confirmed that the results from the study firm were indeed significantly lower in these four areas. On this basis, it was decided that service improvements should first be directed to these four areas.

\section{Identify High Leverage Improvement Area(s)}

With limited resources and more than one area requiring improvement, it was necessary to concentrate planned change in the area where the most significant returns would be expected. The principle of "leverage" illustrates that small, wellfocused, corrective actions, if they are appropriately implemented both temporally and functionally and for a reasonable cost, can produce significant and enduring improvements in performance (Senge 1990). Thus, the issue of which of these four areas will provide the greatest leverage had to be determined.

Initially, it was thought that by focusing improvement efforts in the area with the greatest leverage would also provide the largest return on the effort expended, 
and so logically, the goal was to identify the problem area having the highest potential for improvement. At the law firm, however, there was not a significant difference in the importance ratings between the four areas of concern. In addition, it was noted that different options were potentially available for improving each of these four areas and each planned change was associated with a different expected level of effectiveness and cost structure. Hence, even if one area was perceived to be significantly more important, the potential effectiveness and expected cost associated with improving it may eliminate it from further consideration. Thus, along with a problem area's relative importance, the estimated impact and expected cost of each improvement option need to be incorporated when determining the leverage associated with potential planned change. To address these concerns, a "Leverage Factor" was developed. This simple measure states that the leverage factor (LF) for a proposed change is a function of the area's importance (I) times the ratio of the estimated effectiveness (E) to the expected cost $(C)$ of the planned change. More specifically: $L F=I x(E / C)$.

Table 1 illustrates the application of this relationship to two different options for addressing each of the four major areas of new client concern. By defining the importance (I) for an area of concern as the average of the clients' mean ratings from the benchmark firms' minus the new clients' mean rating for the study firm, its impact in this situation was greatly attenuated. Effectiveness (E) estimates were made after the improvement team discussed their expectations relative to each proposed implemented change. A 1 to 5 scale was used with 1 representing a minor improvement and 5 being the most desirable outcome. This approach to estimating effectiveness metric seemed appropriate to minimize nonfunctional debate over the impact of a potential change on new client perceptions. With regard to determining the cost (C) estimate for each option, it seemed reasonable to use another 1 to 5 point scale with 1 representing the lowest cost and 5 reflecting the highest cost. This approach sought to minimize the delay associated with developing more accurate estimates of expected costs associated with implementing the proposed change.

Contrary to initial thinking, the results of this systematic approach to determining the highest leverage action identified a simple, low-cost, intervention that promised a relatively effective return. The option of sending a map to a new client that showed the firm's location provided the greatest leverage. This option had the greatest E/C ratio, and consequently, became most desirable in this situation. Thus, by employing a simple intervention which provided new clients with clearer directions to the firm's geographical location, the study firm was able to achieve the greatest impact in improvement efforts. It is interesting to note that this option addresses the location accessibility issue in an indirect, rather than a direct, manner.

\section{Perform Selective Sensitivity Analyses}

Like most decision-aiding models, the LF computation relies on data that are estimated or averaged and that depend upon an expected, yet uncertain, future. In these 
Table 1

\begin{tabular}{|c|c|c|c|c|c|}
\hline $\begin{array}{l}\text { (Di } \\
\text { Major area of new } \\
\text { client concern }\end{array}$ & $\begin{array}{c}\text { (I) } \\
\text { Importance } \\
\text { ifference between avera } \\
\text { for benchmarked } \\
\text { firm and new firm) }\end{array}$ & $\begin{array}{c}\text { Suggested } \\
\text { Improvement } \\
\text { Option/Alternative }\end{array}$ & $\begin{array}{l}\text { (E) } \\
\text { stimated } \\
\text { ectiveness } \\
\text { ale: } 1 \text { to } 5 \text {, } \\
\text { ost effective) } \\
\end{array}$ & $\begin{array}{c}\text { (C) } \\
\text { Expected cost } \\
\text { (scale: } 1 \text { to } 5 \\
5=\text { highest cost) } \\
\end{array}$ & $\begin{array}{c}\text { (LF) } \\
\text { Leverage Factor } \\
\text { (Larger number } \\
\text { means greater leverage) }\end{array}$ \\
\hline $\begin{array}{l}\text { Appointment } \\
\text { convenience }\end{array}$ & $\begin{array}{c}1.35 \\
(4.88-3.53)\end{array}$ & $\begin{array}{l}\text { 1. Meet at clients' office } \\
\text { 2. Meet after normal business hours }\end{array}$ & $\begin{array}{l}3 \\
4\end{array}$ & $\begin{array}{l}3 \\
3\end{array}$ & $\begin{array}{l}1.35 \\
1.80\end{array}$ \\
\hline $\begin{array}{l}\text { Location } \\
\text { accessibility }\end{array}$ & $\begin{array}{c}1.33 \\
(5.00-3.67)\end{array}$ & $\begin{array}{l}\text { 1. Provide map to client } \\
\text { 2. Relocate to central business district }\end{array}$ & $\begin{array}{l}3 \\
5\end{array}$ & $\begin{array}{l}1 \\
5\end{array}$ & $\begin{array}{l}3.99 \\
1.33\end{array}$ \\
\hline $\begin{array}{l}\text { Appearance of } \\
\text { office }\end{array}$ & $\begin{array}{c}1.33 \\
(5.00-3.67)\end{array}$ & $\begin{array}{l}\text { 1. New furnishings } \\
\text { 2. Renovation by professional interior designer }\end{array}$ & $\begin{array}{r}4 \\
5\end{array}$ & $\begin{array}{l}3 \\
4\end{array}$ & $\begin{array}{l}1.77 \\
1.66\end{array}$ \\
\hline $\begin{array}{l}\text { Waiting time before } \\
\text { meeting with staff }\end{array}$ & $\begin{array}{c}1.38 \\
(4.78-3.40)\end{array}$ & $\begin{array}{l}\text { 1. Secretary initiates meeting } \\
\text { 2. Solicitor initiates meeting }\end{array}$ & $\begin{array}{l}3 \\
5\end{array}$ & $\begin{array}{l}2 \\
3\end{array}$ & $\begin{array}{l}2.07 \\
2.21\end{array}$ \\
\hline
\end{tabular}


types of situations, it is incumbent upon the analyst to perform a sensitivity or "whatif" analysis. As previously noted, sensitivity analysis can be defined as the examination of the impact of reasonable changes on the estimated or expected variable values in a decision model (Eschenbach, 1992). The LF for the improvement intervention "send map showing location of study firm for initial appointment with new client" has been calculated to be 3.99 which is about 1.8 time greater than the next most attractive action ("reduce client wait time by having the solicitor start the meeting"). While the cost estimate can be confidently estimated to have a value of 1 , there is some uncertainty surrounding the effectiveness rating of 3 . If the effectiveness rating was reduced to 2, the selected intervention would have a LF of 2.66 and still be most favored. While additional "what-if" analyses can be performed to evaluate other possible or probable scenarios, the improvement team believed that the other estimates were "reasonable" and elected to not pursue sensitivity analyses further.

\section{Check for Synergistic Relationships Among Solution Alternatives}

Thus far, the focus has been on identifying and verifying the improvement alternative that has the greatest leverage. To this end, it has been assumed that each of the four problem areas was independent of any other area. However, in most organization settings, different factors are co-dependent and can dynamically influence one another, so it is relevant to design an action plan that will address multiple areas with a coordinated set of changes. Thus, it is appropriate to consider the concurrent implementation of several improvement options in a systemic manner.

Synergy is an important concept in systems thinking. It involves the realization that a system's performance is often greater than the sum of the performance of its individual subsystems. In another words, due to the interaction between the components, the total effectiveness exceeds the sum of the effects obtained from the independent functioning of the components. Thus, in the development of an action plan, it is necessary to select a set of options that will interact in a productive manner to achieve their individual goals while concurrently providing a disproportional gain in overall system effectiveness. This approach provides an overt recognition that a coordinated improvement strategy, as detailed in an action plan, will incorporate a set of mutuallysupportive methods that should positively influence one another.

With regard to the development of an action plan for the study firm, synergy can be realized by identifying a set of mutually-reinforcing tactics which will address each of the four major areas of concern, plus increase the client's overall perception of the quality of services received. This process can be initiated by identifying several options for addressing at least two of the concerns and then creatively combining them into a coordinated policy. To illustrate, the following policy could be implemented to address the first two major areas of concern listed in Table 1, namely, "scheduling the initial appointment at a convenience time for the client" and "improving the client's accessibility to law firm's office": Instruct Article Clerks to be (1) extremely flexible in accommodating any reasonable re- 
quest by a new client for an initial appointment (even scheduling it after normal business hours, or if all else fails, agreeing to meet at the client's office), and (2) fax the client (within the next hour) written confirmation of their appointment time and, whenever appropriate, a map detailing the office location and clear directions on how to travel to the facility.

\section{Finalize Action Plan}

The resultant action plan would include a coordinated set of alternatives sequenced for implementation, implementation schedule, table of personnel and their respective responsibilities, set of performance expectations, and a procedure for monitoring actual performance results emanating from the pilot project implementation. Institutionalizing any policy change would occur after an assessment was made of the results from the pilot project.

\section{Summary and Conclusions}

While several conceptual frameworks are available to guide a $\mathrm{Cl}$ team as they proceed systematically toward improving a process, two of the most popular do not incorporate some of the better-known concepts from systems thinking. Based on the underlying logic for process improvement associated with the Deming Cycle and the Jointer 7 Step Method, a new framework for process improvement has been developed. This new framework builds on the general sequence of steps associated with these well-known problem solving and process improvement approaches while incorporating several relevant systems thinking concepts.

A case study was presented to illustrate how these systems concepts might be applied at a small law firm that is designing an action plan to improve customer satisfaction. After analyzing customer-provided audit information, the law firm was able to identify four areas where improvements were needed. This is a critical first step in designing and implementing an action plan to increase client satisfaction with the service process. The concept of leverage was considered by examining the relative effectiveness and cost of the proposed interventions in concert with the importance of the improvement area where they are focused. Performing a sensitivity analysis of the relative, yet estimated, measures of expected benefits and costs provides some assurance that the results from using the high leverage factors assigned to preferred options are relatively robust. As a consequence, further refinement of these effectiveness and cost metrics was not necessary in this case study. The fourth step in developing the action plan is to employ the concept of synergy. This requires that multiple interventions designed to address several improvement areas be creatively coordinated to take advantage of positive interactions between improvement opportunities and options. Finally, the action plan is solidified and the implementation of a coordinated set of improvement actions is able to occur. 
Relative to the study firm, several new policies were implemented as a result of this study. First, maps and directions were faxed to new clients immediately after appointment times were confirmed. Second, meetings beyond normal business hours were approved by the senior partners in an effort to provide flexibility to meet client's preferences. Third, in the event that the clients is unable to travel to the law office, arrangements could be made for the Article Clerk to meet with the client at his/her office. Thus, policy changes have incorporated a highly desired set of mutually-reinforcing tactics.

Unsolicited feedback from law firm clients has been positive. One of the senior partners reports that business at the firm is growing at a healthy rate even during the recent recession in Hong Kong. Currently, the principals are considering a potential new site for expansion.

\section{References}

Brassard, M., \& Ritter, D. (1994). The memory jogger II. Methuen, MA: GOAL/QPC.

Cheney, A.B., Sims. H.P., \& Manz, C.C. (1994). Teams and TQM. Business Horizons. 37 (5), 16-25.

Conway, E.C. (1993). Basic concepts. In Christopher, W.F., \& Thor, C.G. (eds.), Handbook for productivity measurement and improvement. Cambridge, MA: Productivity Press.

Deming, W.E. (1982). Quality, productivity, and competitive position. Cambridge, MA: MIT Center for Advanced Engineering Study.

Deming, W.E. (1986). Out of crisis. Cambridge, MA: MIT Press.

Dettmer, H.W. (1997). Goldratt's theory of constraints. Milwaukee, WI: ASQC Quality Press.

Eschenbach, T.G. (1992). Spiderplots versus tomado diagrams for sensitivity analysis. Interfaces, $22(6), 40-46$.

Fitzsimmons, J., \& Fitzsimmons, M. (1998). Service management: Operations, strategy and information technology 2nd ed. New York: Irwin/McGraw-Hill.

Goldratt, E.M. (1994). Its not luck. Great Barrington, MA: North River Press.

Hill, T. (1994). Manufacturing strategy 2nd ed. Chicago: Irwin.

Imai, M. (1986). Kaizen: The key to Japan's competitive success. New York: McGrawHill.

Jointer Associates. (1990). Jointer 7 step method. Madison, WI: Jointer Associates. 
Juran, J.M. (1989). Juran on leadership for quality. New York: Free Press.

Koljonen, E.L., \& Reid, R.A. (1998a). Synergy in TOC thinking processes and system dynamic models. Santa Fe, NM: Paper presented at POMS98 Conference.

(1998b). Identifying service customer concerns: Using a walk-through audit and the analytic hierarchy process. Proceedings of the 29 th National Conference of the Decision Sciences Institute. Las Vegas, NV: DSI.

Melam, E.H. (1993). Process management. New York: McGraw-Hill.

Schoderbek, P.P., Schoderbek, C.G., \& Kefalas, A.G. (1990). Management systems 4th ed. Chicago: Irwin.

Scholtes, P.R. (1988). The team handbook. Madison, WI: Jointer Associates,

Schonberger, R.J., \& Knod, E.M. (1997). Qperations management 6th ed. Chicago: Irwin.

Senge, P. (1990), The fifth discipline. New York: Doubleday.

Tague, N. (1995). The quality toolbox. Milwatkee, WI: ASQC Quality Press.

Walton, M. (1986). The Deming management method. New York: Putnam Publishing.

Richard A. Reid is a Professor of Operations Management in the Anderson Schools of Management at the University of New Mexico where he teaches undergraduate and graduate courses in systems and production/operations management. He received a $\mathrm{Ph} . \mathrm{D}$ in systems research and an MBA from Ohio State University, as well as a BSME from Case Institute of Technology. Dr. Reid has published over 100 articles in national and international journals and is the co-author of a book entitled: Competitive Hospitals. He has been a consultant to private sector and governmental agencies in the application of total quality tools to address production, service, and delivery problems under the guise of process improvement.

Elsa L. Koljonen received her Bachelor of Laws degree with honors from the University of Hong Kong. She was a legal practitioner in Hong Kong prior to emigrating to the United States in 1992. Ms Koljonen earned her MBA in Operations Management from the University of New Mexico in 1997. Currently residing in Arizona, she is the commodity manager for the Assembly Capital Equipment Development Group at the Intel Corporation. 